\title{
Long-term expansion of directly reprogrammed keratinocyte-like cells and in vitro reconstitution of human skin
}

Jie Zheng ${ }^{1,2}$, Wonjin Yun ${ }^{1,2}$, Junghyun Park ${ }^{1,2}$, Phil Jun Kang ${ }^{1,2}$, Gilju Lee $^{3}$, Gwonhwa Song $^{2 *}$, In Yong Kim ${ }^{{ }^{*}}$ and Seungkwon You ${ }^{1,2^{*}}$

\begin{abstract}
Background: Human keratinocytes and derived products are crucial for skin repair and regeneration. Despite substantial advances in engineered skin equivalents, their poor availability and immunorejection remain major challenges in skin grafting.
\end{abstract}

Methods: Induced keratinocyte-like cells (iKCs) were directly reprogrammed from human urine cells by retroviral transduction of two lineage-specific transcription factors BMI1 and $\triangle \mathrm{NP63a}(\mathrm{BN})$. Expression of keratinocyte stem cell or their differentiation markers were assessed by PCR, immunofluorescence and RNA-Sequencing. Regeneration capacity of iKCs were assessed by reconstitution of a human skin equivalent under air-interface condition.

Results: BN-driven iKCs were similar to primary keratinocytes (pKCs) in terms of their morphology, protein expression, differentiation potential, and global gene expression. Moreover, BN-iKCs self-assembled to form stratified skin equivalents in vitro.

Conclusions: This study demonstrated an approach to generate human iKCs that could be directly reprogrammed from human somatic cells and extensively expanded in serum- and feeder cell-free systems, which will facilitate their broad applicability in an efficient and patient-specific manner.

Keywords: Induced keratinocyte-like cells, Urine cells, Direct lineage reprogramming, Long-term expansion, Skin reconstitution

\section{Background}

Major skin injuries and diseases caused by thermal burns, surgical incisions, infection, trauma, or chronic ulcers require medical intervention to heal properly and can be life-threatening in severe cases. In particular, burn injuries are often devastating and have long-term

\footnotetext{
* Correspondence: ghsong@korea.ac.kr; iykim@korea.ac.kr; bioseung@korea.ac.kr

${ }^{2}$ Institute of Animal Molecular Biotechnology, College of Life Sciences and Biotechnology, Korea University, Seoul 02841, Republic of Korea

'Laboratory of Cell Function Regulation, Department of Biotechnology, College of Life Sciences and Biotechnology, Korea University, Seoul 02841, Republic of Korea

Full list of author information is available at the end of the article
}

physical and psychosocial impacts. Such injuries can result in cosmetic disfigurement, meaning sufferers have to cope with an alteration in their appearance [1]. Current therapeutic protocols are based on debridement and application of skin grafts to protect the exposed layers and to allow reconstitution of the damaged portion. Autologous grafting allows full integration into the donor site; however, this approach is limited by the amount of skin available for wound coverage and rapid re-epithelialization as well as the creation of additional deficits, especially in cases with severe burns and skin morbidities [2,3]. Allogeneic and xenogeneic skin grafts are also employed due to their better availability and

C C The Author(s). 2020 Open Access This article is licensed under a Creative Commons Attribution 4.0 International License, which permits use, sharing, adaptation, distribution and reproduction in any medium or format, as long as you give appropriate credit to the original author(s) and the source, provide a link to the Creative Commons licence, and indicate if changes were made. The images or other third party material in this article are included in the article's Creative Commons licence, unless indicated otherwise in a credit line to the material. If material is not included in the article's Creative Commons licence and your intended use is not permitted by statutory regulation or exceeds the permitted use, you will need to obtain permission directly from the copyright holder. To view a copy of this licence, visit http://creativecommons.org/licenses/by/4.0/. The Creative Commons Public Domain Dedication waiver (http://creativecommons.org/publicdomain/zero/1.0/) applies to the data made available in this article, unless otherwise stated in a credit line to the data. 
accessibility of material for wound closure. However, their clinical use is limited by the recipient's immune response, which leads to cellular destruction, and therefore these grafts are only used as temporary biologic dressings [4]. Consequently, much attention has been paid to generating an unlimited and immunocompatible graft material that provides therapeutic benefit as a skin replacement. One approach is to use autologous keratinocytes that have been expanded in vitro for $2-4$ weeks [5, 6]. Proof-of-principle studies demonstrated that these cells induce rapid re-epithelialization; however, the functional and aesthetic outcomes, clinical feasibility, and cost-benefit relationship of remote culture facilities remain unclear $[7,8]$.

Stem cells and derived products are potential therapeutics in dermatology and reconstructive surgery. Substantial advances in differentiating pluripotent stem cells, including embryonic stem cells (ESCs) and induced pluripotent stem cells (iPSCs), mean that patient- and disease-specific stem cells can be obtained, which will help to improve understanding of human development and disease processes, develop new therapeutics, and pave the road to personalized medicine [9]. However, these approaches carry the risks of tumor formation and immune rejection, and their application is hampered by ethical concerns $[9,10]$. Alternatively, reprogramming of somatic donor cells, bypassing an intermediate pluripotent stage, provides important benefits including karyotypic stability, homogeneity of the target cell population, low tumorigenic risk, patient specificity, and time- and labor-efficient processing [11]. Intensive efforts to manipulate cell fates employing a set of lineage-specific transcription factors and small molecules recently led to the generation of various cell types, including adult stem/progenitor cells (oligodendrocyte progenitor cells, hematopoietic progenitor cells, neural stem cells, and limbal stem cells) and somatic cells (neurons, cardiomyocytes, hepatocytes, and pancreatic $\beta$ cells) [11]. Despite these impressive exhibitions of phenotypic conversion, only one study reported transcription factordriven transdifferentiation of human somatic cells into skin keratinocyte lineage cells, to the best of our knowledge. Chen et al. reported that two keratinocyte-specific transcription factors, called $\triangle \mathrm{NP} 63 \alpha$ and KLF4 (NK), can directly convert human neonatal dermal fibroblasts and human colon carcinoma cells into cells with a basal keratinocyte phenotype [12]. These keratinocyte-like cells (KCs) resemble primary keratinocytes (pKCs) in terms of their morphology, biological characteristics, and global gene expression, but fail to form a stratified epidermis.

Epidermal stem/progenitor populations, found in epidermis with high proliferative capacity, and differentiated keratinocytes are distributed in tightly adherent layers of the epidermis and are organized into distinct zones according to their differentiation stages. Differentiating keratinocytes progressively emerge from the proliferative basal layer and replenish the upper layer by undergoing renewal throughout life, thereby desquamating the dead envelope at the skin surface [13]. In the basal layer of the epidermis, keratinocytes not only maintain tissue homeostasis, but also participate in skin repair following injury $[14,15]$. However, the restricted in vitro proliferative potential of isolated epidermal populations, including keratinocyte stem/progenitor cells, hinders their preclinical and clinical applications. Cultured keratinocytes were reported to irreversibly lose their stem cell properties upon passage $[16,17]$. Using isolated murine keratinocyte subpopulations, Redvers et al. and Blanpain et al. showed that the expansion and functional properties of keratinocytes are only retained in a specific environment $[18,19]$. Long-term expandability of keratinocytes is an indispensable prerequisite for potential medical applications, including cell therapy, disease modeling, drug screening, and reconstitution of functional skin in vitro.

Here, we established induced KC (iKC) lines from human urine-derived cells, which were obtained from two healthy donors (one male and one female), by forced expression of two transcription factors called BMI1 and $\triangle \mathrm{NP} 63 \alpha(\mathrm{BN})$ under keratinocyte culture conditions. Urine-derived cells provide the following advantages: i) these cells are available regardless of a person's age, gender, or health condition; ii) these cells can be collected by a simple, safe, inexpensive, and non-invasive procedure; and iii) primary cells can be easily isolated without enzymatic digestion [20]. BN-driven iKCs (BN-iKCs) closely resembled pKCs in terms of their morphology, biological characteristics, in vitro differentiation capacities, and global gene expression. More importantly, BNiKCs stably expanded in serum- and feeder cell-free conditions and self-assembled to form stratified skin equivalents in vitro.

\section{Methods \\ Cell culture}

pKCs (human neonatal epidermal keratinocytes; Thermo Fisher Scientific, Waltham, MA, USA) were cultured in a Matrigel (Corning, New York, NY, USA)-coated plate in keratinocyte serum-free medium (KSFM). This medium was a 1:1 ratio of Defined Keratinocyte-SFM (Thermo Fisher Scientific):Keratinocyte-SFM (Thermo Fisher Scientific) containing 1\% penicillin/streptomycin (P/S; Lonza, Basel, Switzerland), $2 \mathrm{mM} \mathrm{L-glutamine}$ (Lonza), $10 \mu \mathrm{M} \mathrm{Y-27632} \mathrm{(Tocris,} \mathrm{Bristol,} \mathrm{UK),} \mathrm{and} 1 \mu \mathrm{M}$ A-83-01 (Tocris). When pKCs reached $\sim 80 \%$ confluency, they were subcultured in ReagentPack ${ }^{\mathrm{Tm}}$ Subculture Reagents (Lonza) in a Matrigel (Corning)-coated 
plate. Mouse 3 T3-J2 cells (Kerafast, Boston, MA, USA) were maintained in high-glucose DMEM (Hyclone, Logan, UT, USA) supplemented with $10 \%$ fetal calf serum (Thermo Fisher Scientific), $1 \% \mathrm{P} / \mathrm{S}$, and $2 \mathrm{mML}$ glutamine.

\section{Isolation and culture of urine cells}

Urine samples were obtained from two healthy donors (one male and one female). Cells were isolated from $1000 \mathrm{ml}$ of urine by modifying a previously described method [21]. Briefly, cells in urine samples were collected by centrifugation and seeded in a gelatin (Sigma, St. Louis, MO, USA)-coated 12-well plate in urine primary culture medium, and then $500 \mu \mathrm{l}$ of fresh medium was added every day. After 4-5 days, the medium was replaced by urine proliferation medium for further culture of attached urine cells (regarded as passage 1). Urine primary culture medium was DMEM/F12 (Hyclone) containing 10\% fetal bovine serum (FBS; Hyclone), 1\% penicillin/streptomycin/fungizone solution (Hyclone), and $2 \mathrm{mML}$-glutamine. Urine proliferation medium was a 1:1 ratio of high-glucose DMEM:REGM (Lonza) containing 5\% FBS, $0.5 \% \mathrm{P} / \mathrm{S}, 2 \mathrm{mM} \mathrm{L-glutam-}$ ine, $1 \%$ non-essential amino acid solution (Thermo Fisher Scientific), $2.5 \mathrm{ng} / \mathrm{ml}$ basic fibroblast growth factor (bFGF; PeproTech, London, UK), and $2.5 \mathrm{ng} / \mathrm{ml} \mathrm{epi-}$ dermal growth factor (EGF, PeproTech).

\section{Construction of retroviral plasmids}

The human BMI1 fragment was excised from the pBabe-hBMI1 vector (provided by Goberdhan P. Dimri) using the restriction enzyme EcoRI (Takara Bio Inc., Kusatsu, Japan) and inserted into the EcoRI site of the pMXs-puro backbone vector (Cell Biolabs Inc., San Diego, CA, USA). The human $\triangle$ NP63 $\alpha$ fragment was excised from the deltaNp63alpha-FLAG expression vector (plasmid \#26979; Addgene, Watertown, NY, USA) using the restriction enzymes BamHI (Takara Bio Inc.) and NotI (Takara Bio Inc.), and inserted into the BamHI and NotI site of the pMXs-puro backbone vector. The constructed plasmids were confirmed by sequencing.

\section{Generation of induced KCs}

Retroviruses were produced by transfecting the PT67 amphotropic packaging cell line (Clontech Laboratories, Mountain View, CA, USA) with pMXs-based retroviral vectors encoding human BMI1, $\triangle \mathrm{NP} 63 \alpha$, and KLF4 (plasmid \#17219, Addgene) using a lipofectamine 2000based protocol (Thermo Fisher Scientific). Retroviruscontaining supernatants were harvested at $72-120 \mathrm{~h}$ post-transfection, filtered with a $0.45 \mu \mathrm{m}$ sterile syringe filter (Millipore, Burlington, VT, USA), and concentrated by ultracentrifugation $\left(20,000 \mathrm{~g}, 1.5 \mathrm{~h}, 4{ }^{\circ} \mathrm{C}\right)$.
Urine cells at passage 3 were infected with the resulting retroviruses, either alone or in combination. After 2 days, infected urine cells were re-seeded at a density of $2 \times 10^{4}$ cells per well in a 12-well plate with a mitomycin-inactivated 3 T3-J2 feeder layer, at an initial seeding density of $2 \times 10^{4}$ cells $/ \mathrm{cm}^{2}$, in keratinocyte growth medium (KGM) containing 2\% FBS (2\% FKGM), which was refreshed every 2 days for $\sim 2$ weeks. Formed keratinocyte colonies were picked and re-plated as individual clones in a type I collagen-coated 24-well plate in KGM containing 10\% FBS (10\% FKGM). A picked single colony was further selected and expanded in $10 \%$ FKGM. FKGM was a 3:1 ratio of DMEM/F12 containing $2 \%$ or $10 \% \mathrm{FBS}, 1 \% \mathrm{P} / \mathrm{S}, 2 \mathrm{mM}$ L-glutamine, $5 \mu \mathrm{g} / \mathrm{ml}$ insulin (Sigma), $0.5 \mu \mathrm{g} / \mathrm{ml}$ hydrocortisone (Sigma), $8.3 \mathrm{ng} /$ $\mathrm{ml}$ cholera toxin (Sigma), $1.37 \mathrm{ng} / \mathrm{ml}$ triiodothyronine (Sigma), $52.8 \mu \mathrm{g} / \mathrm{ml}$ ascorbic acid 2-phosphate (Sigma), $20 \mathrm{ng} / \mathrm{ml} \mathrm{EGF}$, and $10 \mu \mathrm{g} / \mathrm{ml}$ adenine (Sigma) [22]. To generate $\mathrm{iKCs}$ in serum-free conditions, BN-infected urine cells at passage 3 or human foreskin fibroblasts (CRL-2522, ATCC, Manassas, VA, USA) at passage 5 were seeded at a density of $2 \times 10^{4}$ cells per well in a 12well plate with a mitomycin-inactivated 3 T3-J2 feeder layer in 2\% FKGM and cultured for 5-6 days. Thereafter, the medium was replaced by KSFM and cells were cultured for a further 7-8 days. Single formed colonies were picked, selected, and propagated in a type I collagen-coated plate in KSFM.

\section{Immunofluorescence}

Cultured cells were fixed in $4 \%$ paraformaldehyde solution (Biosesang, Seongnam, South Korea) for $20 \mathrm{~min}$ at room temperature and washed three times with $1 \times$ DPBS (Welgene Inc., Gyeongsan, South Korea). Permeabilization and blocking were performed with $1 \times$ DPBS containing 5\% donkey serum (Millipore) and 0.3\% Triton X-100 (Sigma) for $30 \mathrm{~min}$ at room temperature to detect nuclear/cytoplasmic proteins or with $1 \times$ DPBS containing $5 \%$ donkey serum and $0.1 \%$ Triton X-100 for $10 \mathrm{~min}$ at room temperature to detect surface proteins. Thereafter, cells were washed three times and incubated with primary antibodies diluted in $1 \times$ DPBS containing $5 \%$ donkey serum at $4{ }^{\circ} \mathrm{C}$ overnight. After incubation, cells were washed three times and incubated with secondary antibodies diluted in $1 \times$ DPBS at room temperature for $60 \mathrm{~min}$. Nuclei were stained with DAPI (Sigma). The antibodies are listed in Supplementary Table S1.

\section{RT-PCR and real-time PCR}

Total RNAs were isolated from cells using TRIzol (Thermo Fisher Scientific), and cDNAs were synthesized using RT PreMix (Bioneer, Daejeon, South Korea) and the oligo $\mathrm{dT}$ primer (Bioneer) according to the 
manufacturers' instruction. Gene fragments were amplified using $25 \mathrm{ng}$ of cDNA, specific primers (Bioneer), and PCR PreMix (Bioneer) in a total reaction volume of $20 \mu$ l. All RT-PCR amplifications were verified to be in the linear range. Real-time PCR was performed using a CFX Connect ${ }^{\text {tw }}$ Real-Time PCR Detection System (BioRad, Hercules, CA, USA) and SYBR Green Supermix (Bio-Rad). The housekeeping gene GAPDH was used as an internal standard. The primer sequences are listed in Supplementary Table S2.

\section{Colony-forming assay}

Cells were seeded at a density of $2.5 \times 10^{3}$ cells per well in a 6-well plate with a mitomycin-inactivated 3 T3-J2 feeder layer and cultured in 10\% FKGM or KSFM for 7 days. Thereafter, cells were fixed in $10 \%$ formalin for 20 min at room temperature and stained with $0.1 \%$ crystal violet solution for $20 \mathrm{~min}$ at room temperature.

\section{Differentiation of pKCs and iKCs}

To generate terminally differentiated keratinocytes, pKCs (passage 2) or $\mathrm{BN}$-iKCs (passage 6) were seeded in a collagen-coated 6-well plate and maintained until they reached $80-90 \%$ confluency. Thereafter, cells were differentiated in Keratinocyte-SFM containing $1.2 \mathrm{mM}$ $\mathrm{CaCl}_{2}$ for 5 days and $100 \mathrm{nM}$ Phorbol 12-myristate 13acetate (PMA, Sigma) for 2 days. Differentiation of sebocytes was performed as previously described [23]. pKCs (passage 2) or BN-iKCs (passage 6) were seeded at a density of $2 \times 10^{5}$ cells per well in a 6 -well plate in sebocyte induction medium, which was DMEM/F12 containing 6\% FBS, 2\% human serum (Sigma), 1\% P/S, and $10 \mathrm{ng} / \mathrm{ml}$ EGF, and cultured overnight. Thereafter, the medium was replaced by sebocyte induction medium containing $10 \mathrm{nM}$ insulin, $1 \mu \mathrm{M}$ troglitazone (Cayman, Ann Arbor, MI, USA), $100 \mu \mathrm{M}$ WY14643 (Sigma), and $10 \mathrm{nM}$ DMSO (Sigma) to induce sebocyte differentiation, and cells were cultured for a further 12 days. Differentiated cells were washed twice with $1 \times$ DPBS and fixed with $10 \%$ formalin for $30 \mathrm{~min}$ at room temperature. Fixed cells were washed and pretreated with $60 \%$ isopropanol for $2 \mathrm{~min}$ and incubated with $0.5 \%(\mathrm{w} / \mathrm{v})$ Oil red $\mathrm{O}$ solution for $30 \mathrm{~min}$ at room temperature. Stained cells were rinsed with $60 \%$ isopropanol and imaged under a phase-contrast microscope (Olympus, Tokyo, Japan).

\section{RNA-sequencing and analysis}

Total RNA was isolated using TRIzol. RNA quality was assessed using an RNA 6000 Nano Chip and Agilent 2100 bioanalyzer (Agilent Technologies, Santa Clara, CA, USA). Libraries were prepared using $\sim 2 \mu \mathrm{g}$ of total RNA and a SMARTer Stranded RNA-Seq Kit (Clontech Laboratories). mRNA was isolated from total RNA using a Poly(A) RNA Selection Kit (Lexogen, Greenland, AR,
USA) in accordance with the manufacturer's instructions and used for cDNA synthesis and shearing. Indexing was performed using Illumina indexes 1-12. The enrichment step was carried out using PCR. Subsequently, libraries were checked using the Agilent 2100 bioanalyzer with a DNA High Sensitivity Kit to evaluate the mean fragment size. Quantification was performed on a StepOne RealTime system (Thermo Fisher Scientific) using a Library Quantification Kit. High-throughput paired-end $100 \mathrm{bp}$ sequencing was performed using a HiSeq 2500 system (Illumina, San Diego, CA, USA).

The alignment files were obtained from mapped mRNA-seq reads using TopHat software [24]. Differentially expressed genes were determined based on counts from unique and multiple alignments using coverage in Bedtools [25]. RT (read count) data were processed based on the quantile normalization method using EdgeR within R (R Development Core Team, 2016) and Bioconductor [26]. The alignment files were also used to assemble transcripts, estimate their abundances, and detect differential expression of genes or isoforms using cufflinks or DESeq2 (FDR adjusted $P<0.05$ ). Fragments per kilobase of exon per million fragments (FPKM) was calculated to determine the expression levels of the gene regions. Gene classification was based on searches performed with DAVID (http://david.abcc.ncifcrf.gov/).

\section{In vitro skin reconstitution}

Skin equivalents were generated using an air-liquid interface method as previously reported [27, 28]. Foreskin fibroblasts (CRL-2522; ATCC, Manassas, VA, USA) were encapsulated in a rat tail type I collagen gel (Corning), plated into a 6-well cell culture insert $(3.0 \mathrm{~mm}$ polycarbonate membrane, Corning) at a density of $2 \times$ $10^{5}$ cells per well to form an acellular layer, and cultured in fibroblast medium for $\sim 1$ week. pKCs at passage 2, $\mathrm{BN}-\mathrm{MiKCs}$ at passage 6 , and male donor-derived urine cells (M-UCs) at passage 3 were seeded onto the formed acellular layer at a density of $3 \times 10^{5}$ cells per well and cultured in keratinocyte differentiation medium 1 for 1 week, during which time the medium was replaced with fresh medium every 2 days. Thereafter, the surface of cultured cells was exposed to air for air-liquid interface culture, keratinocyte differentiation medium 1 was replaced every 2 days for 1 week, and then keratinocyte differentiation medium 2 was replaced every 2 days for an additional 1 week. Fibroblast medium was high-glucose DMEM containing 10\% FBS, $1 \% \mathrm{P} / \mathrm{S}, 2 \mathrm{mM} \mathrm{L}$-glutamine, $4 \mathrm{ng} / \mathrm{ml} \mathrm{bFGF} \mathrm{(PeproTech),} \mathrm{and} 50 \mu \mathrm{g} / \mathrm{ml}$ ascorbic acid 2-phosphate. Keratinocyte differentiation medium 1 was a $1: 1$ ratio of DMEM/F12 containing $1.39 \mathrm{mg} / \mathrm{ml}$ $\mathrm{NaHCO}_{3}, 1 \% \mathrm{P} / \mathrm{S}, 2 \mathrm{mM}$ L-glutamine, $0.4 \mu \mathrm{g} / \mathrm{ml}$ hydrocortisone, $5 \mu \mathrm{g} / \mathrm{ml}$ insulin, $5 \mu \mathrm{g} / \mathrm{ml}$ transferrin (Sigma), $0.02 \mathrm{nM}$ triiodothyronine, $0.18 \mathrm{mM}$ adenine, $0.1 \mathrm{mM}$ 
ethanolamine (Sigma), $0.1 \mathrm{mM}$ phosphorylethanolamine (Sigma), $0.0053 \mathrm{nM}$ selenium (Sigma), $50 \mu \mathrm{g} / \mathrm{ml}$ gentamycin (Lonza), $1.2 \mathrm{mM} \mathrm{CaCl}_{2}$, and 2\% FBS. Keratinocyte differentiation medium 2 was keratinocyte differentiation medium 1 containing 1\% FBS instead of 2\% FBS.

\section{Immunohistochemistry}

Samples cultured at the air-liquid interface were fixed in $4 \%$ paraformaldehyde at $4{ }^{\circ} \mathrm{C}$, embedded in paraffin, and dissected into $4 \mu \mathrm{m}$ thick sections. Sections were stained with hematoxylin and eosin (H\&E, Sigma) for routine histological evaluation. For immunohistochemistry, sections were deparaffinized with xylene, and antigen recovery was performed by boiling in citrate buffer ( $\mathrm{pH}$ 6.0) for $10 \mathrm{~min}$. Next, the sections were stained with specific antibodies against KRT14, Loricrin, and Involucrin using a Vectastain ABC Kit (Vector Laboratories, Burlingame, CA, USA). Nuclei were counterstained with hematoxylin (Sigma). The antibodies are listed in Supplementary Table S1.

\section{Statistical analysis}

Data are expressed as mean values \pm SD in $n$ independent observations. Data were compared using a one-way ANOVA and the paired two-tailed Student's t test. $P<$ $0.05, P<0.01$, or $P<0.001$ was considered statistically significant.

\section{Results}

\section{Generation of iKCs from human urine cells}

Urine samples contain heterogeneous cell populations and adherent cells removed from the renal tubules or urethras $[29,30]$. Due to their good accessibility and high availability, human urine cells are considered to be a promising source of material for cellular reprogramming and personalized cell therapies [20]. Previous studies showed that urine cells isolated from the same donor exhibit two different types of cobblestone-like (Type I) and elongated (Type II) morphology during isolation, and the latter cells possessed a higher proliferative potential and reprogramming efficiency than the former cells [21, 29]. Accordingly, Type II urine cells were chosen for this study. Prior to directly reprogramming urine cells into iKCs, we investigated expression of several epidermal keratinocyte lineage markers (KRT15, KRT14, ITGA6, KRT10, and Involucrin) in urine cells. None of these markers were expressed (Figure. S1A). Based on a previous report of NK-driven conversion of human neonatal foreskin fibroblasts into iKCs [12], we first infected human urine cells, with retroviruses encoding NK and cultured them in 2\% FKGM with 3 T3-J2 feeder cells (Fig. 1a, S2A). NK-overexpressing urine cells exhibited a colony morphology and expressed keratinocyte stem cell markers (Fig. 1c-e and S2A); however, these cells failed to expand in 10\% FKGM for more than three passages (Figure. S3E). Considering that KLF4 is highly expressed during induction into terminal differentiated keratinocytes $[31,32]$ and $\triangle \mathrm{NP} 63 \alpha$-triggered epithelial-mesenchymal transition of normal primary human epidermal keratinocytes [33], we hypothesized that BMI1, rather than KLF4, would improve reprogramming of urine cells into iKCs and acquisition of epidermal stemness. BMI1, a stem cell factor in neural and hematopoietic stem cells [34, 35], is detected in epider$\mathrm{mal}$ basal/suprabasal layers, and its ectopic expression contributes to survival and proliferation of keratinocytes and reversal of $\triangle \mathrm{NP} 63 \alpha$-triggered epithelialmesenchymal transition by inhibiting the transforming growth factor $\beta$ (TGF $\beta$ ) signaling pathway [33, 36, 37]. Accordingly, urine cells were infected with retroviral vectors encoding BMI1, $\triangle \mathrm{NP} 63 \alpha$, and KLF4 either alone or in combination (B, N, K, BN, BK, NK, and BNK). Putative iKCs, which exhibited a holoclone morphology similar to that of expandable keratinocytes, were observed upon infection with $\mathrm{BNK}$ or BN. In the adult human skin, it has been reported that CD71 ${ }^{\mathrm{dim}}$, ITGA6 ${ }^{\mathrm{Bri}}$ and KRT15 are more dominant in deep rete ridges where stem and transient amplifying cells are abundant, suggesting that KRT15 and ITGA6 could serve as a specific marker for identification of keratinocyte stem and transient amplifying epidermal cells [38]. A high percentage of the colonies expressed KRT15 and ITGA6, whereas these markers were not expressed in noninfected urine cells and feeder cells (Fig. 1a-c, S1, and S2). BN-overexpressing urine cells had the highest $\mathrm{KRT}_{15}{ }^{+} \mathrm{ITGA}^{+}$colony-forming efficiency (CFE), and these colonies expressed stem cell markers at a comparable level as pKCs (Fig. 1d, e). These findings indicate that urine cells are efficiently converted into keratinocyte-like colonies via overexpression of BN.

\section{Selection and long-term culture of $\mathrm{BN}$-iKCs}

A homogeneous population of $\mathrm{BN}-\mathrm{iKCs}$ was attained by single-colony picking and KRT15/ITGA6 immunostaining for further expansion and maintenance (Fig. 2a). We selected three $\mathrm{KRT} 15^{+} \mathrm{ITGA}^{+}$colonies from putative $\mathrm{BN}-\mathrm{iKCs}$ (referred to as line $\mathrm{BN} 28-2, \mathrm{BN} 28-5$, and BN28-6) and one KRT15 ${ }^{+} / \mathrm{ITGA}^{+}$colony from each of putative BNK-, NK-, and $\mathrm{N}-\mathrm{iKCs}$ (referred to as line BNK21-11, NK16-6, and N20-10, respectively) (Fig. 2b and S3A-D). BN-iKCs co-expressed KRT15 and ITGA6; however, KRT15 expression was lower in BNK21-11, NK16-6, and N20-10 cells (Fig. 2b and S3A-C). Intriguingly, $\mathrm{BN}-\mathrm{iKCs}$ not only expressed normal stem cell markers (KRT15, KRT4, ITGA6, and GJB2), but also CD200 and ANGPTL2, which are specifically expressed in human hair follicle epithelial stem cells (HFSCs) (Fig. 2c). Meanwhile, the current standard method for long- 


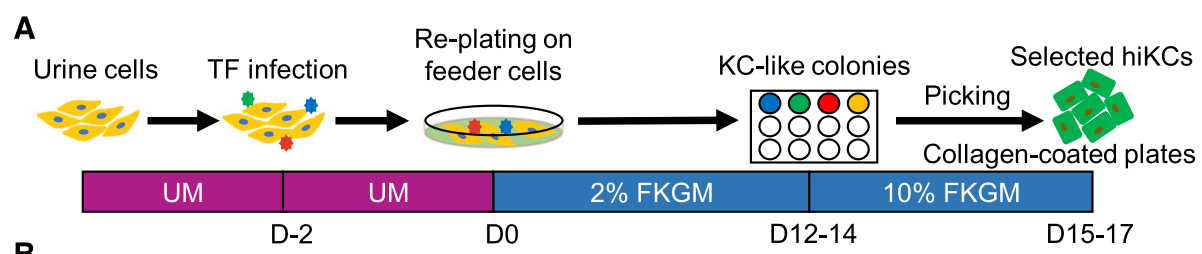

B
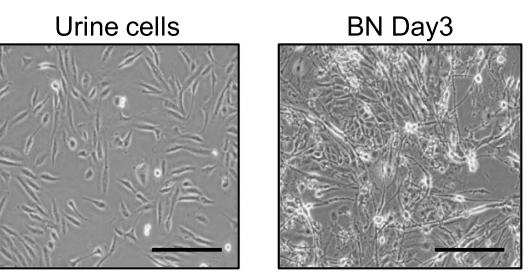

C

BNK
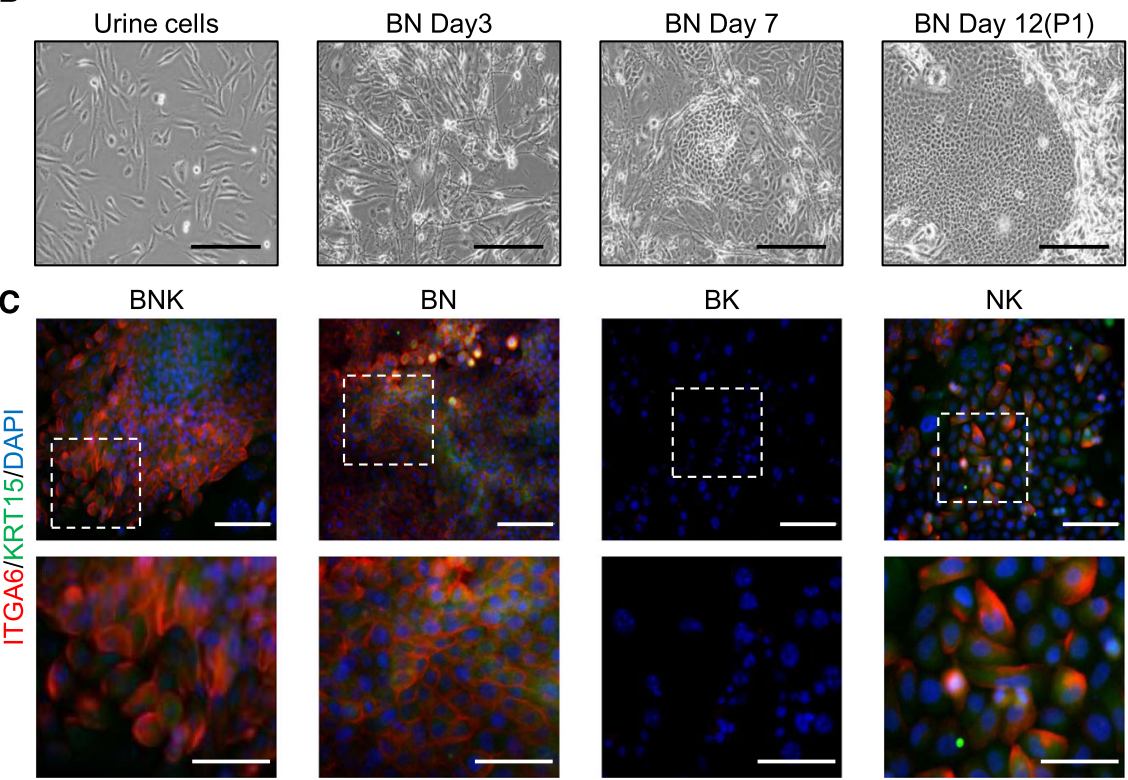

D
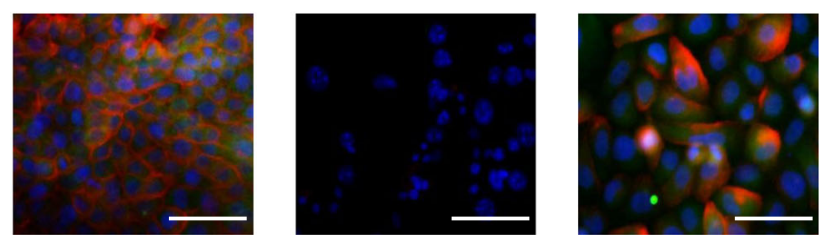

E
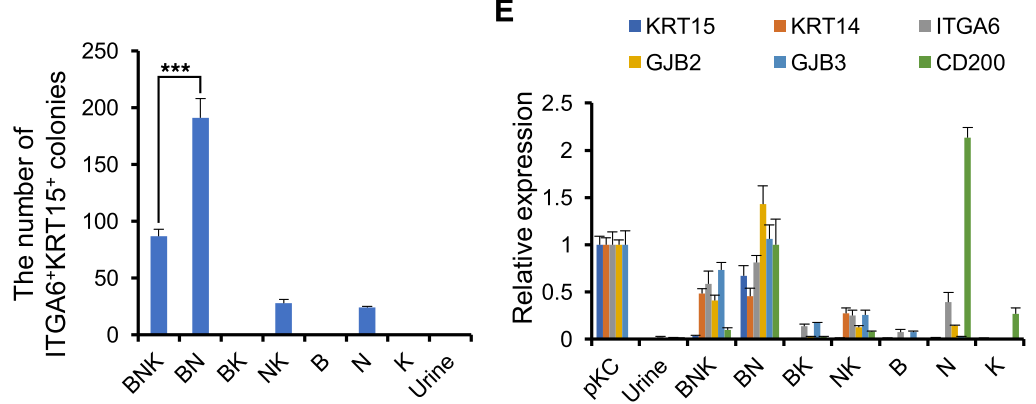

Fig. 1 Direct reprogramming of human urine cells into iKCs. a Schematic diagram of the induction of iKCs from human urine cells. Transcription factors (TFs). b Morphological changes of urine cells during direct reprogramming. At passage 3, urine cells were infected with retroviruses encoding BN in urine proliferation medium. BN-infected urine cells were plated in 2\% FKGM on a 3 T3-J2 feeder layer to form holoclones. At day 12, the holoclones were picked for further expansion and characterization. Scale bars $=500 \mu \mathrm{m}$. c Immunostaining of the stem cell markers KRT15 and ITGA6 in BNK-, BN-, BK-, and NK-infected cells with specific antibodies at day 12 post-induction. Nuclei were counterstained with DAPI. The lower row shows magnified images of the boxed areas in the upper row. Scale bars $=200 \mu \mathrm{m}$ (upper), $100 \mu \mathrm{m}$ (lower). $\mathbf{d}$ Number of

ITGA6 ${ }^{+}$KRT15 $5^{+}$colonies formed by BNK-, BN-, BK-, NK-, B-, N-, and K-infected cells and urine cells at 12 days post-induction. Cells were seeded at a density of $2 \times 10^{4}$ cells per well in a 12-well plate. Data represent the mean \pm SEM. ${ }^{* * *} P<0.001$. e qRT-PCR analysis of relative expression of stem cell markers in BNK-, BN-, BK-, NK-, B-, N-, and K-infected cells, urine cells, and pKCs at 12 days post-induction. Data represent the mean \pm SEM. GAPDH was used as a loading control. B, BMI1; N, $\triangle \mathrm{NP} 63 \mathrm{a}$; and K, KLF4

term expansion of human keratinocytes, which was pioneered by Rheinwald and Green [39], uses a feeder layer of 3 T3-J2 mouse fibroblasts, which are irradiated to prevent their proliferation and to suppress differentiation of keratinocytes. Importantly, the presence of other cell types or serum carries the risks of viral infection and pathogen transmission in a clinical setting and affects the morphology and biology of target cells, which complicates the interpretation of research results [40, 41]. Therefore, we attempted to expand KRT15 ${ }^{+} \mathrm{ITGA}^{+}$ $\mathrm{BN}-\mathrm{iKCs}$ on a collagen-coated plate in feeder cell-free conditions $[42,43]$. The proliferation rate of BNK21-11 cells was higher than those of NK16-6 and N20-10 cells and further their population doubling time significantly increased in comparison with that of $\mathrm{BN}-\mathrm{iKCs}$ at passage $8(>110 \mathrm{~h})$, leading to growth arrest at the next passage 
A

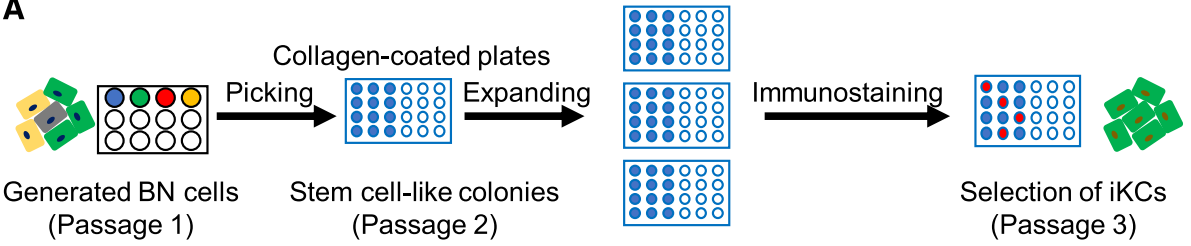

B
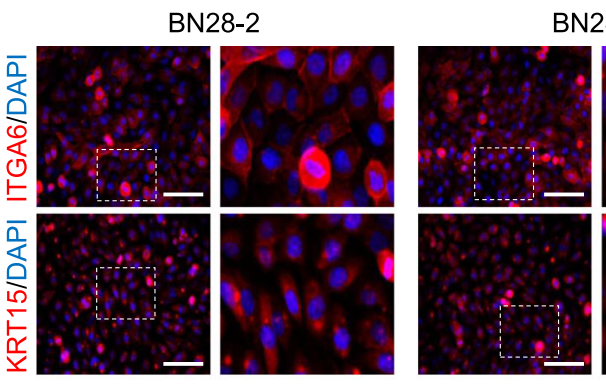

BN28-5
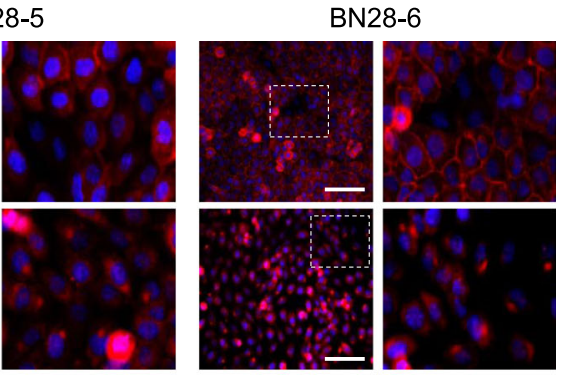

C

D
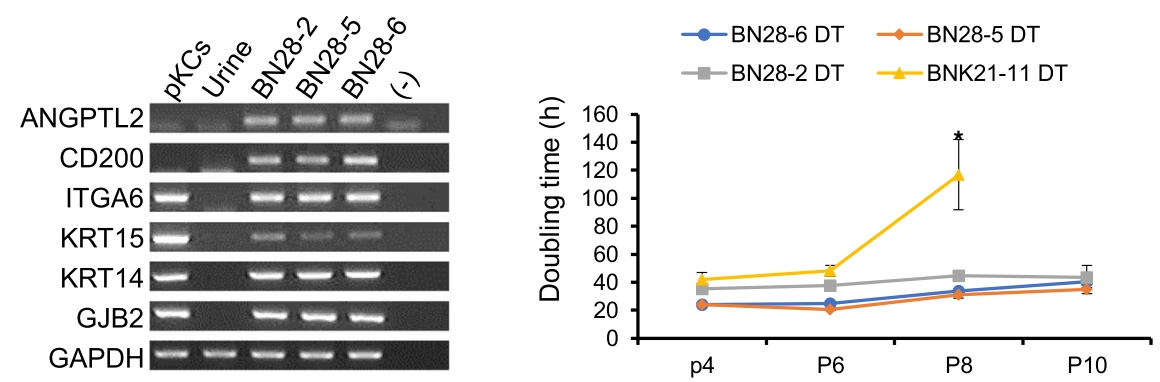

E
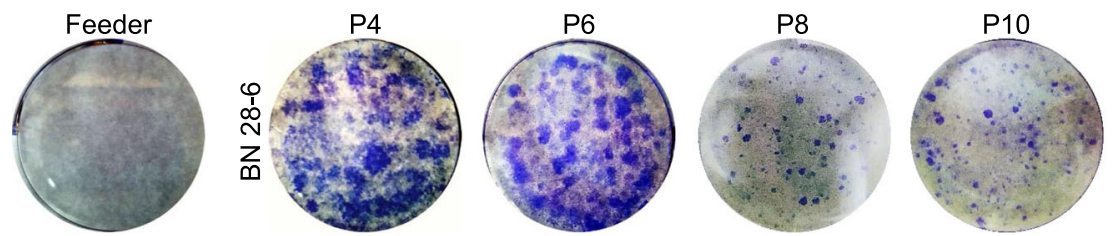

Fig. 2 Selection, characterization, and expansion of BN-iKCs. a Schematic diagram of the selection of ITGA6 ${ }^{+} K R T 15^{+}$iKCs. $\mathbf{b}$ Immunostaining of selected ITGA6 ${ }^{+}$KRT15 ${ }^{+}$BN-iKCs (BN28-2, BN28-5, and BN28-6) at passage 3 with specific antibodies against ITGA6 and KRT15. Nuclei were counterstained with DAPI. Images on the right are magnified views of the boxed areas in images on the left. Scale bars $=200 \mu \mathrm{m}$. $\mathbf{c}$ RT-PCR analysis of stem cell marker expression in pKCs, urine cells, and BN-iKCs. $\mathbf{d}$ Doubling time of BN-iKCs and BNK21-11 cells during long-term expansion. Cells were seeded at a density of $5 \times 10^{4}$ cells per well in a 6-well plate. Data represent the mean \pm SEM. * $P<0.05$. e Colony-forming assay of BN-iKCs during long-term expansion. BN-iKCs were seeded at a density of $0.25 \times 10^{4}$ cells per well in a 6 -well plate with a $3 \mathrm{T3}$-J2 feeder layer and cultured for 1 week. The plates were stained with crystal violet

(Fig. 2d). In addition, the colony-forming assay showed that $\mathrm{BN}-\mathrm{iKC}$ colonies formed in the first six passages and then their size and number gradually decreased, losing of the characteristic of stemness, while BNK21-11 cells did not form colonies (Fig. 2e and S3F). NK16-6 and N20-10 cells could not be lasted more than 3 passages and exhibited senescence-like morphological changes and increased apoptosis (Figure. S3E). By contrast, the population doubling time of $\mathrm{BN}-\mathrm{iKCs}$ was $20-40 \mathrm{~h}$ and remained stable for at least 10 passages
(Fig. 2d). These results suggest that BN-iKCs can undergo long-term expansion in feeder cell-free culture systems, while maintaining expression of stem cell markers and stemness properties.

\section{In vitro differentiation potential of $\mathrm{BN}$-iKCs}

In vitro exposure to a high concentration of extracellular calcium induces differentiation of undifferentiated keratinocytes into mature keratinocytes [44]. The capacity of $\mathrm{BN}$-iKCs to differentiate into keratinocytes was assessed 
by qPCR analysis and immunostaining. Expression of differentiated keratinocyte markers (KRT1/KRT10, Involucrin, and Filaggrin) was increased in differentiated BNiKCs, while expression of stem cell markers (KRT15 and ITGA6) was concurrently decreased (Fig. 3a, b and S1C). KRT1 and KRT10 are a pair of keratins specifically expressed in suprabasal cells. In addition, expression of genes (KRT14, KRT8, and KRT18) that are enriched in both basal and differentiated keratinocytes did not significantly differ between undifferentiated and terminally differentiated BN-iKCs (Fig. 3a, b). Neither stem cell nor mature keratinocyte markers were expressed in urine cells cultured in differentiation conditions (Figure. S4). Abundant oil droplets were detected in the cytoplasm of $\mathrm{BN}-\mathrm{iKC}$ - and $\mathrm{pKC}$-derived sebocytes by Oil red $\mathrm{O}$ staining (Fig. 3c and S5), while no oil droplets were observed in urine cells (Figure. S5E, F). Furthermore, the reproducibility of this protocol was repeatedly evaluated utilizing female donor-derived urine cells (F-UCs). BNtransduced F-UCs formed keratinocyte-like colonies
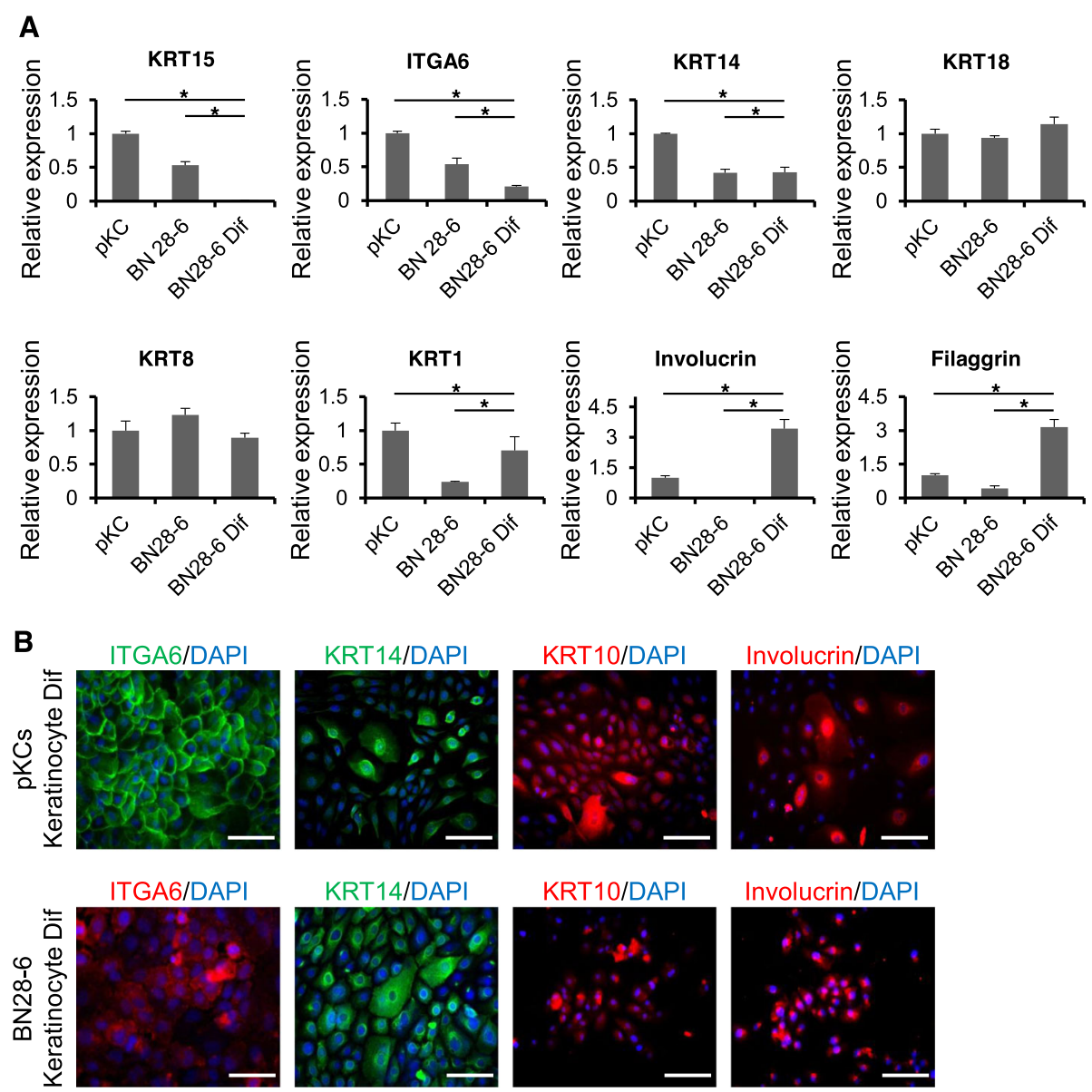

C
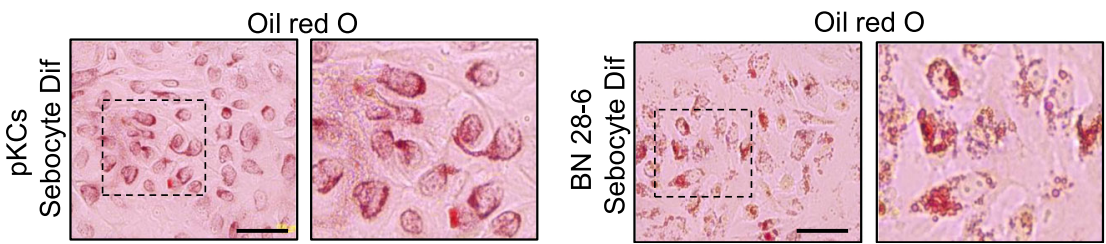

Fig. 3 Differentiation potential of BN-iKCs in vitro. a Relative mRNA expression of keratinocyte lineage markers in pKCs, BN28-6 cells, and mature keratinocytes differentiated from BN28-6 cells. Stem cell markers: KRT15 and ITGA6; basal/suprabasal markers: KRT14, KRT8, and KRT18; differentiated markers: KRT1, Involucrin, and Filaggrin. GAPDH was used as a loading control. Data represent the mean \pm SEM. ${ }^{*} P<0.05$. $\mathbf{b}$ Immunofluorescence analysis of keratinocyte markers (ITGA6, KRT14, KRT10, and Involucrin) in mature keratinocytes differentiated from pKCs and BN28-6 cells. Nuclei were counterstained with DAPI. Scale bars $=200 \mu \mathrm{m}$. c Oil red O staining of sebocytes differentiated from pKCs and BN28-6 cells. Images on the right are magnified views of the boxed areas in images on the left. Scale bars $=200 \mu \mathrm{m}$ 
(Figure. S6A), expressed stem cell markers at the mRNA and protein levels (Figure. S6B, C), and had the potential to differentiate into mature keratinocytes (Figure. S6D). These results suggest that $\mathrm{BN}$ amplification is essential to establish $\mathrm{KC}$ identity in human urine cells.

\section{Generation and long-term expansion of BN-iKCs in serum- free culture conditions}

FBS is an undefined and highly complex mixture containing various macromolecules, hormones, growth factors, lipids, and proteins. Variability in FBS in terms of donor, country, collection method, and processing unpredictably influence cultured cells [45]. For example, the presence of fetuin, high-density lipoprotein, plateletderived growth factor, or TGF $\beta$ reportedly contributes to terminal differentiation of mouse epidermal keratinocytes and a reduction in CFE [46]. Similarly, the CFE of $\mathrm{BN}$-iKCs decreased upon long-term serial passage in FKGM, leading us to speculate that FBS reduces the CFE. We therefore investigated whether the present protocol for long-term expansion and maintenance of $\mathrm{BN}$-iKCs could be performed in KSFM (Fig. 4a). Initially, 2\% FKGM was used to stably culture and transduce Mor F-UCs with BN, and then replaced by KSFM for further processing. After 12-14 days, keratinocyte-like colonies were collected and expanded in KSFM in type I collagen-coated plates. The selected colonies of $\mathrm{BN}-\mathrm{iKCs}$ induced from M- or F-UCs (referred to as BN-MiKCs and BN-FiKCs, respectively) expressed exogenous BMI1 and $\triangle \mathrm{NP} 63 \alpha$ (Figure S7A, B). At passage 4, Both BNMiKCs and BN-FiKCsexhibited a keratinocyte-like morphology and expressed stem cell markers (Fig. 4b, c, and S8A-C). Both BN-MiKCs and BN-FiKCs had the potential to differentiate into mature keratinocytes (Fig. 4d) and sebocytes (Fig. 4e and S9C). The expression of exogenous $\triangle \mathrm{NP} 63 \alpha$ showed a decrease in both BNMiKCs and BN-FiKCs during terminal differentiation of keratinocytes (Figure S7C). Furthermore, we investigated the response of $\mathrm{BN}-\mathrm{iKCs}$ to a PKC activator, PMA, known as keratinocyte terminal differentiation inducer [47]. Consistent with previous study, exposure of BNMiKCs and BN-FiKCs to PMA allowed the expression of terminal differentiation markers (Involucrin and Loricrin) and blocked the expression of early differentiation marker (KRT10) (Figure S7D).

To assess whether BN-MiKCs and BN-FiKCs retained a long-term self-renewal potential, we cultured them in KSFM for at least 20 passages. These cells exhibited robust expression of typical stem cell markers (Fig. 5a, b, and S8D-F). In contrast with culture in the presence of FBS, KSFM contributed to stable colony formation and preservation of the differentiation potential of $\mathrm{BN}$ MiKCs and BN-FiKCs during long-term expansion (Fig. 5c, d, S8G, and S9A, B). Overall, these results demonstrate that iKCs can be generated and expanded in serum- and feeder cell-free culture conditions.

\section{Global gene expression profiles of $\mathrm{BN}-\mathrm{iKCs}$}

We compared the global transcriptome profile of human urine cell-derived iKCs with those of parental urine cells and pKCs by RNA-sequencing. Hierarchical clustering $(\mathrm{FDR}<0.05)$ showed the genome-wide conversion of $\mathrm{M}$ and F-UCs into BN-MiKCs and BN-FiKCs, respectively, and these cells exhibited a high degree of similarity to pKCs (Fig. 6a). Moreover, the principal component analysis (PCA) indicated that $\mathrm{BN}-\mathrm{iKCs}$ successfully separated from UCs and more closed to pKCs (Fig. 6b). Next, we analyzed significantly changed genes (FDR < 0.05 ) in four comparisons (BN-MiKCs vs. M-UCs, pKCs vs. M-UCs, BN-FiKCs vs. F-UCs, and pKCs vs. F-UCs) by using Venn diagram: 645, 1534, 1449, and 4422 genes were upregulated, while 509, 1965, 1098 and 4008 genes were downregulated, respectively (Fig. 6c and S10A). Compared with parental urine cells, 431 and 429 genes were upregulated and downregulated, respectively, in both $\mathrm{BN}-\mathrm{MiKCs}$ and $\mathrm{pKCs}$, and 889 and 919 genes were upregulated and downregulated, respectively, in both BN-FiKCs and pKCs. Gene ontology (GO) categories related to epidermis processes, including epidermis development, hemidesmosome assembly and keratinocyte proliferation, were significantly enriched in $\mathrm{BN}$ $\mathrm{iKCs}$ and pKCs, while genes related on extracellular matrix organization, ureteric bud development and angiogenesis were highly downregulated (Fig. 6d, e and S10 B, C, D, E).

\section{Reconstitution of a human skin equivalent in vitro}

Upon culture on a layer of dermal fibroblasts with collagen under air-liquid interface conditions, epidermal keratinocytes form stratified sheets and differentiate to establish a three-dimensional (3D) skin equivalent [27, 28]. Skin equivalents reconstituted from patient- and disease-specific cells are a powerful tool to elucidate the molecular processes that affect skin physiology and pathophysiology, to investigate various skin diseases, drug discovery, and therapeutic applications, and to perform skin grafting $[48,49]$. Accordingly, we investigated whether BN-iKCs can reconstitute skin equivalents comparably to pKCs. The skin equivalents generated by $\mathrm{BN}$ iKCs were morphologically similar to those generated by pKCs, and they expressed the basal and suprabasal layer marker KRT14 as well as epidermal differentiation markers such as Involucrin and Loricrin (Fig. 7). As expected, urine cells did not form epidermis-like structures and did not express epidermal markers (Fig. 7). These results demonstrate the tissue-regenerative capacity of $\mathrm{BN}-\mathrm{iKCs}$ and their progeny, implying that our approach 

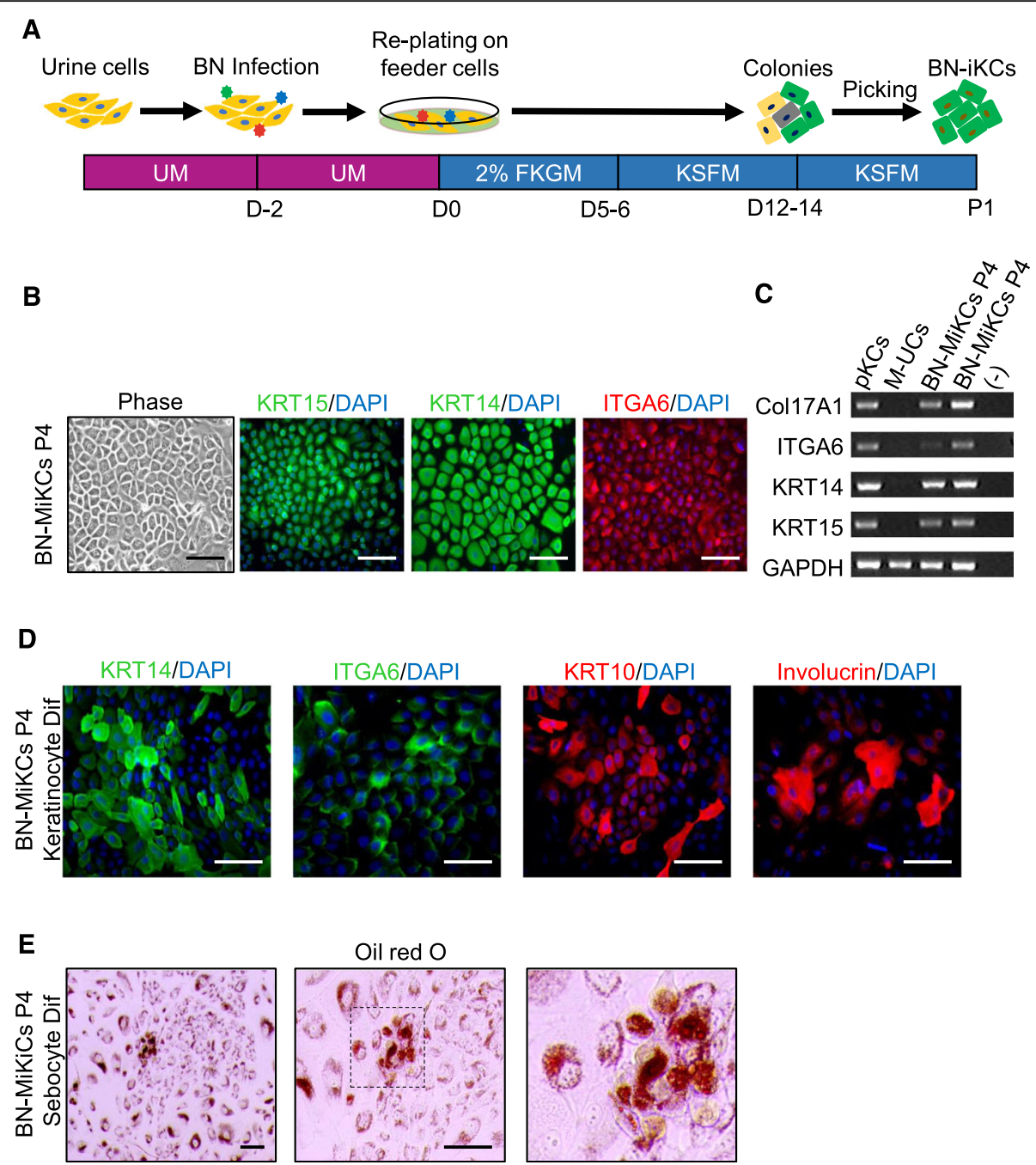

Fig. 4 BN-driven direct reprogramming of M-UCs into iKCs in serum-free conditions. a Schematic diagram of the generation of BN-iKCs. $\mathbf{b}$ Phasecontrast image and immunostaining of stem cell markers (KRT15, KRT14, and ITGA6) in BN-MiKCs at passage 4 selected by single-colony picking. Nuclei were counterstained with DAPI. Scale bars $=200 \mu \mathrm{m}$. c RT-PCR analysis of stem cell markers (Col17A1, ITGA6, KRT14, and KRT15) in pKCs, MUCs, and BN-MiKCs. d Expression of keratinocyte markers (ITGA6, KRT14, KRT10, and Involucrin) in mature keratinocytes differentiated from BNMiKCs. Scale bars $=200 \mu \mathrm{m}$. e Oil red O staining of sebocytes differentiated from BN-MiKCs. The image on the right is a magnified view of the boxed area in the central image. Scale bars $=200 \mu \mathrm{m}$

for generating and expanding iKCs could be translated from the bench to the bedside.

\section{Overexpression of $\mathrm{BN}$ allowed fibroblasts to express keratinocyte stem genes}

To evaluate whether other somatic cell sources are exploited to generate iKCs by overexpression of $\mathrm{BN}$. Human foreskin fibroblasts were transduced with retroviruses encoding BN. These $\mathrm{BN}$-overexpressed fibroblasts exhibited expression of the keratinocyte stem markers in mRNA and protein levels (Figure S11). However, these cells showed a very low reprogramming efficiency and failed in the formation of colonies, suggesting that the choice of the somatic cell source is one of the key drivers for successful direct lineage conversion.

\section{Discussion}

Here, we describe a novel method to directly reprogram human urine cells into long-term expandable iKCs, allowing in vitro reconstitution of personalized skin. This is achieved using two lineage-specific transcription factors, namely, BN, and culture in feeder cell- and serum-free conditions. BN-driven iKCs were similar to pKCs in terms of their morphology, protein expression, $2 \mathrm{D}$ and 3D differentiation potential, and global gene expression profile. Our approach has several advantages over existing methods for clinical trials. First, the present 
A
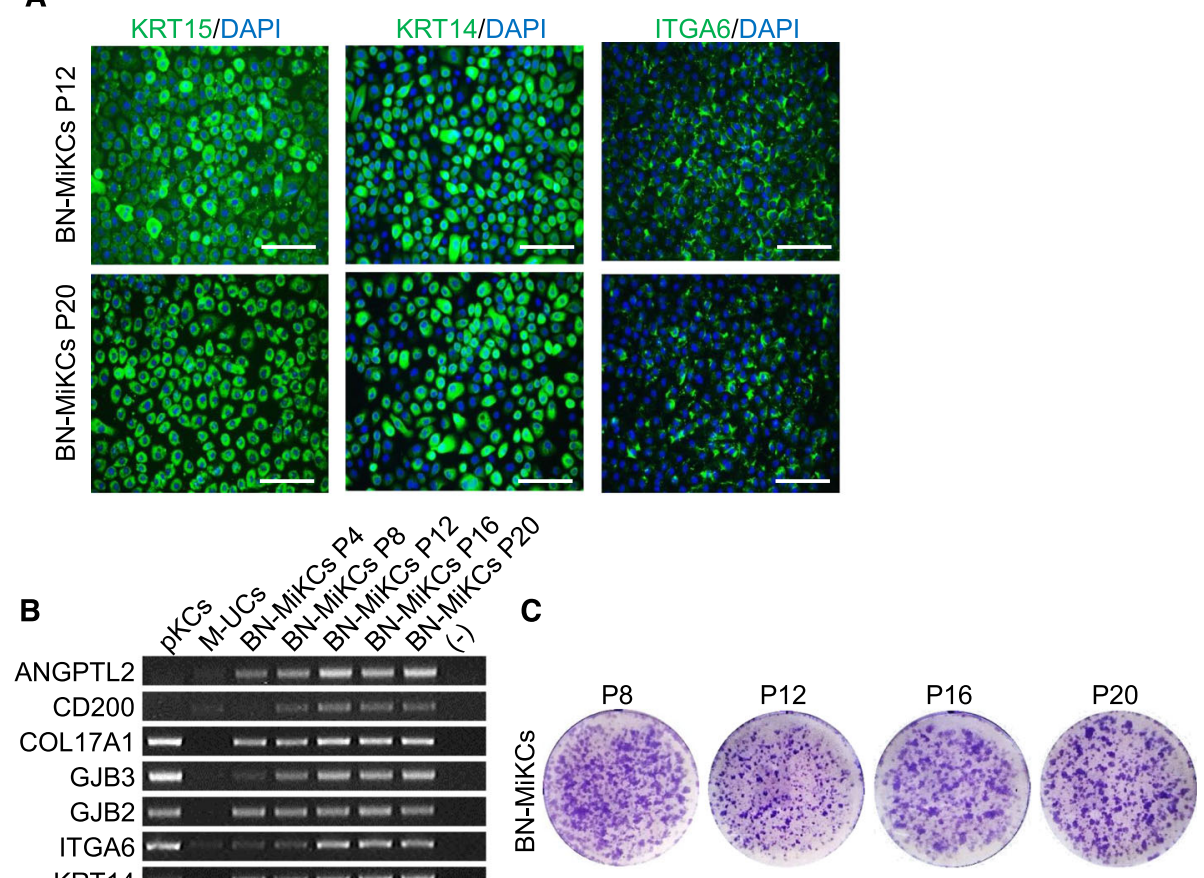

KRT14 $-2-\square$

KRT15 $=-2=$

GAPDH $-\infty$

D
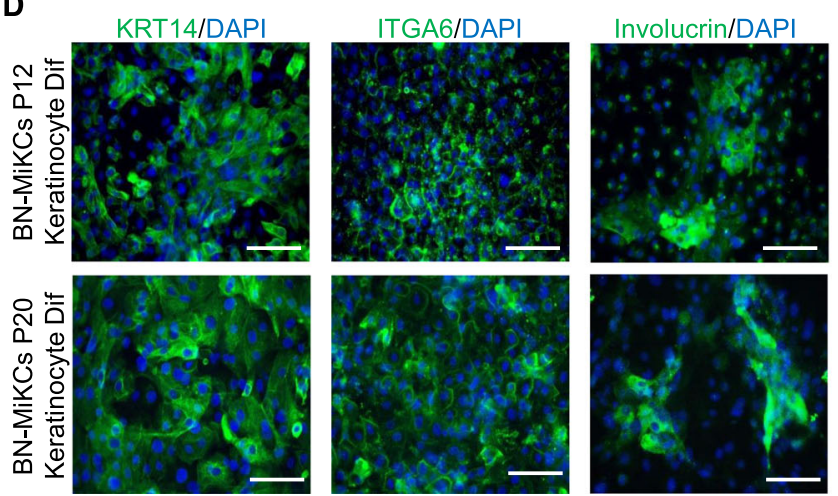

Fig. 5 Long-term propagation and characterization of BN-MiKCs. a Immunofluorescence analysis of stem cell markers (KRT15, KRT14, and ITGA6) in BN-MiKCs at passage 12 and 20. Scale bars $=200 \mu \mathrm{m}$. b mRNA expression of keratinocyte stem cell-specific (Col17A1, GJB3, GJB2, ITGA6, KRT14, and KRT15) and HFSC-specific (ANGPTL2 and CD200) markers in pKCs, M-UCs, and BN-MiKCs at passage 4, 8, 12, 16, and 20. c Colony-forming assay of BN-MiKCs at passage 8, 12, 16, and 20. BN-iKCs were seeded at a density of $0.25 \times 10^{4}$ cells per well in a 6 -well plate with a 3 T3-J2 feeder layer and cultured for 1 week. The plates were stained with crystal violet. d Expression of keratinocyte markers (ITGA6, KRT14, and Involucrin) in mature keratinocytes differentiated from BN-MiKCs at passage 12 and 20. Scale bars $=200 \mu \mathrm{m}$. Nuclei were counterstained with DAPI

protocol reprograms human urine cells, allowing patient-specific therapies to be conducted in a noninvasive manner. Second, direct reprogramming of functional cell types from one lineage to another is a critical tool for clinical trials because it bypasses an intermediate pluripotent stage and thereby minimizes the risk of tumorigenesis after transplantation [50]. Third, compared with iPSC-based approaches using the canonical reprogramming factors OCT4, SOX2, KLF4, and cMYC [51-54], the poor proliferative ability of functional cells converted using lineage-specific transcription factors is a major challenge. The reprogramming strategy into proliferative stem/progenitor cells and acquisition of expandable transient intermediates can generate a larger amount of material for biomedical applications, while maintaining all the therapeutic benefits [4]. In addition, stem/progenitor cells are more desirable for transplantation due to their efficient engraftment and better integration in vivo [55]. Fourth, the generated iKCs are extensively expandable in serum- and feeder cell-free 


\section{A}

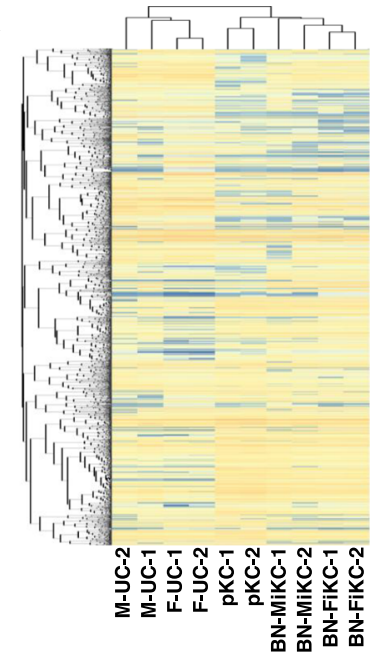

C

Upregulated genes

pKCs vs M-UCs BN-MiKCs vs M-UCs

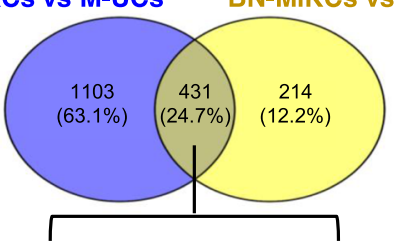

Epidermis development Keratinocyte proliferation

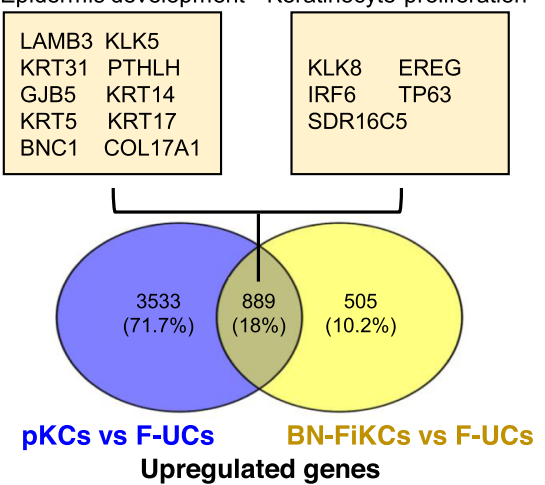

B

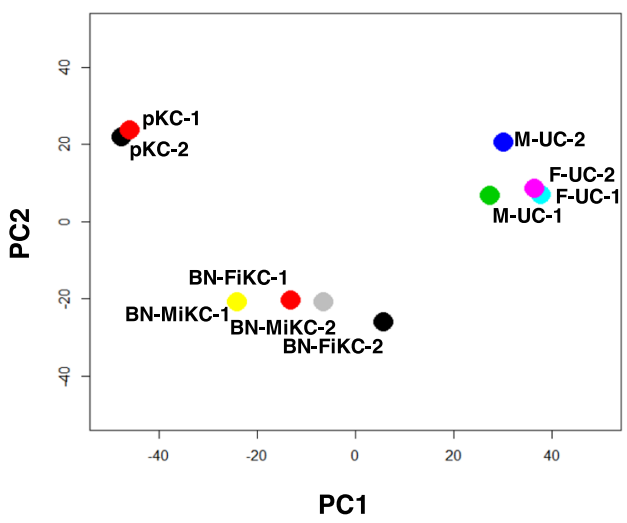

D

Enrichment GO terms (upregulated 431 genes)

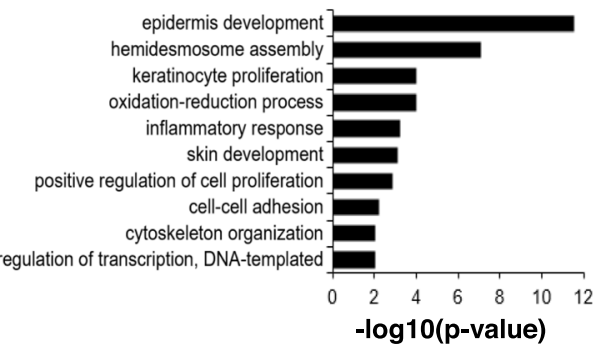

E

Enrichment GO terms (upregulated 889 genes)

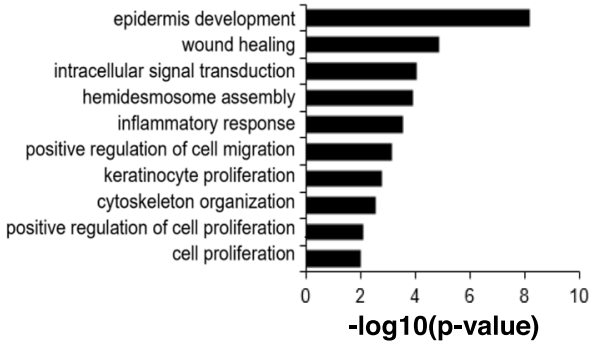

Fig. 6 Global gene expression profiling of BN-iKCs. a Heat map with hierarchical clustering of genes (FDR < 0.05) in M-UCs, F-UCs, pKCs, BN-MiKCs and BN-FiKCs based on RNA-sequencing analysis. Red and blue in the heat map indicate upregulated and downregulated genes, respectively. $\mathbf{b}$ principal component analysis (PCA) of RNA-seq data from M-UCs, F-UCs, pKCs, BN-MiKCs and BN-FiKCs. $\mathbf{c}$ Venn diagram showing the numbers of significantly upregulated genes (FDR < 0.05) in the pKCs vs. M-UCs and BN-MiKCs vs. M-UCs comparisons (upper) and pKCs vs. F-UCs and BNFiKCs vs. F-UCs comparisons (lower). $\mathbf{d}$ and $\mathbf{e} \mathrm{GO}$ analysis of overlapping upregulated genes from (c)

systems. Previous methods for in vitro expansion of epithelial stem cells rely on co-culture with mouse fibroblasts in serum-containing basal medium, which contains undefined and variable mixtures of molecules [39]. In the last decades, substantial efforts have been made to isolate and culture epithelial stem cells in serum-free medium and to retain their undifferentiated state in feeder cell-free conditions [56-58]. Nonetheless, it remains challenging to develop culture conditions that address the safety concerns of regulatory affairs. Finally, the in vitro reconstitution of human skin demonstrated the similarities between the generated iKCs and their in vivo counterparts (pKCs) as well as their regenerative ability, which is a hallmark of stem cells. Although this has been achieved by isolation of epidermal stem cells, a skin equivalent derived from human iKCs has not been previously reported.

Despite the improved expansion of iKCs and successful construction of a human skin equivalent in vitro, clinicians have continually questioned their value versus the risks of retrovirus-mediated gene transfer, which can potential contribute to undesired genotoxicity, 


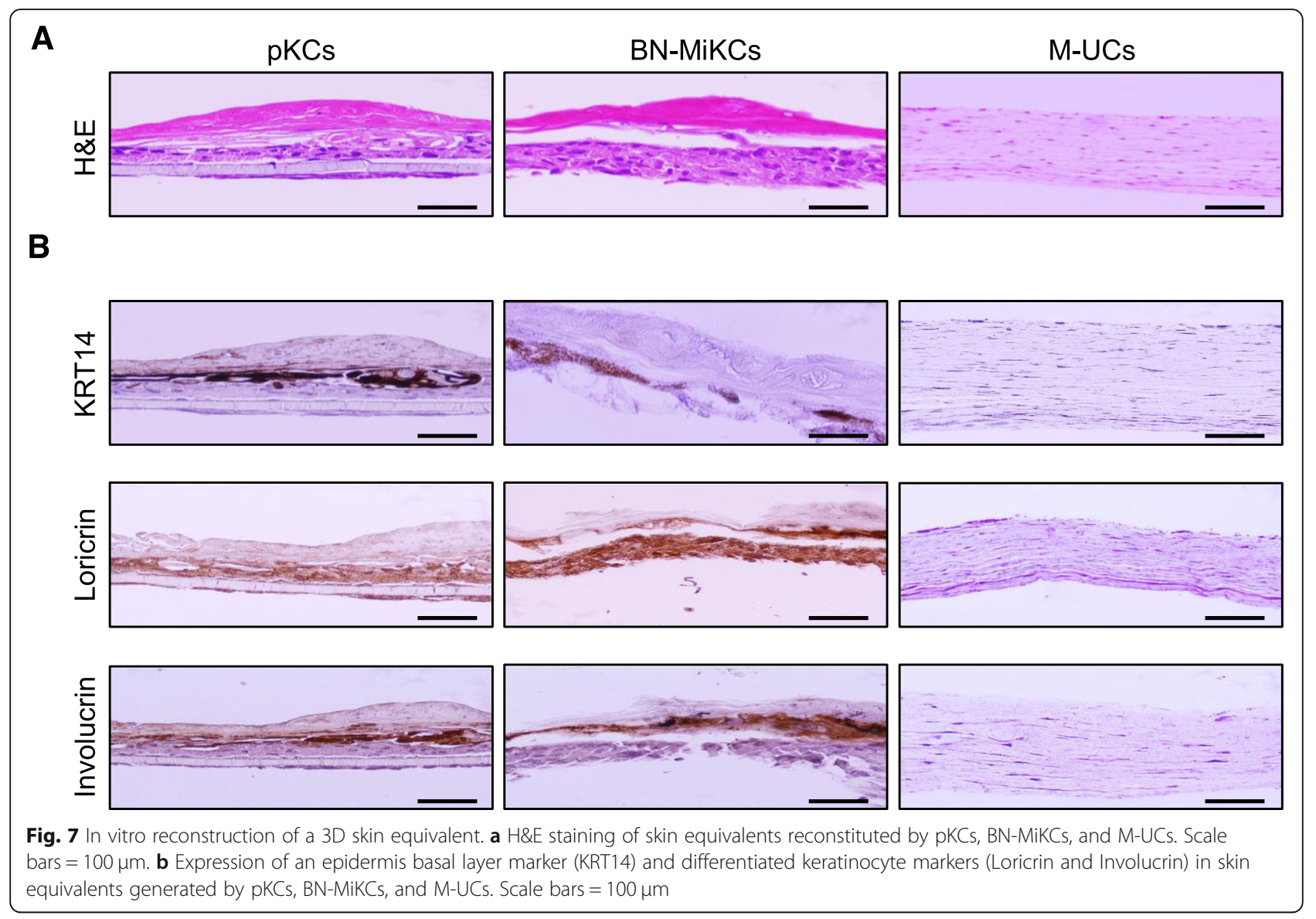

insertional mutagenesis, and tumorigenesis [59]. Various integration-free approaches have been developed to convert cells into iPSCs and adult stem/progenitor cells, including viral (adenoviruses, Sendai viruses, and Creexcisable viruses) [60-63] and non-viral (DNA expression vectors, minicircle vectors, and episomal vectors) [64-67] vectors and non-DNA-based systems (proteins, mRNAs, and chemicals) [68-73]. Thus, further studies of genetic delivery that avoids potential issues associated with viral integration are required to increase the feasibility of clinical trials. Meanwhile, we found that exogenous $\triangle \mathrm{NP} 63 \alpha$ was continuously expressed in $\mathrm{BN}-\mathrm{iKCs}$, while its endogenous expression were not detected, which is consistent with a previous study [12]. $\triangle \mathrm{NP} 63 \alpha$ plays critical roles in maintaining the self-renewal and proliferation capacities of keratinocyte stem/progenitor cells and regulating their differentiation for stratification of the epidermis [74, 75]. Antonini et al. demonstrated that $\triangle \mathrm{Np} 63 \mathrm{\gamma}$ robustly induces endogenous expression of $\triangle \mathrm{NP63 \alpha}$ in HeLa cells [76]. Another study reported that P53 is a potent transcriptional activator of $\triangle \mathrm{NP} 63 \alpha$ in immortalized mammary epithelial cells [77]. Collectively, gene-free methodology for activating endogenously expressed $\triangle \mathrm{NP} 63 \alpha$, mediated by genes such as $\triangle \mathrm{Np} 63 \gamma$ or P53, may be a promising alternative to virus-mediated gene transfer.

In the present study, BN-iKCs expressed HFSC-specific markers (CD200 and ANGPTL2) and successfully differentiated into sebocytes. Nonetheless, hair follicles were not found in nude mice subcutaneously injected with BNiKCs and mouse neonatal dermis cells (data not shown). Based on previous studies [78-80], this inability to induce hair follicle formation may be explained by repression of HFSC markers such as LHX2, LGR5, and LGR6, which contribute to preservation of the self-renewal ability of stem cells and fate specification to whole hair follicles. Thus, BN might only drive reprogramming of human urine cells into iKCs with a partial HFSC phenotype. Generation of iKCs with a full HFSC phenotype may require genes that play essential roles in regulation of hair follicle morphogenesis and specification (i.e., SOX9, TCF3, TCF4, and SNAI2) [81-83]. Moreover, accumulating evidence indicates that epigenetic factors, including ACTL6a, DNMT1, HDAC1, HDAC2, and SUZ12, help to maintain stemness and/or suppress differentiation of HFSCs [8487]. Additional transcription and epigenetic factors could therefore be useful for the acquisition of HFSC properties during induction of iKCs. 


\section{Conclusions}

We demonstrated that human urine cells can be directly reprogrammed into expandable iKCs using a defined set of lineage-specific transcription factors, namely, BN. In addition, the generated iKCs could undergo long-term expansion in serum- and feeder cell-free conditions, and, more importantly, self-assembled to regenerate a fully stratified epithelium sheet in vitro. Further studies for generating integration-free and hair folliculogenic iKCs could offer enormous promise for clinical applications. Nevertheless, this study describes a novel method to generate human iKCs that can undergo long-term expansion, which will facilitate their broad applicability in an efficient and patient-specific manner. In addition, these cells could be used as an in vitro platform to explore the cellular and molecular cues governing skin regeneration and to address scientific or medical questions in dermatology and skin biology.

\section{Supplementary information}

Supplementary information accompanies this paper at https://doi.org/10. 1186/s12929-020-00642-1.

\section{Additional file 1 Table S1. Antibody information used in} Immunofluorescence and Immunohistochemistry. Table S2. Primer information used in RT-PCR and Real-Time PCR. Figure S1. Immunofluorescence analysis of keratinocyte lineage markers. Figure S2. Induction of KCs from human urine cells using several combinations of transcription factors. Figure S3. Selection and further expansion of induced urine cells using several combinations of transcription factors. Figure S4. Differentiation of human urine cells into terminally differentiated KCs. Figure S5. Differentiation into sebocytes. Figure S6. Direct reprogramming of F-UCs into BN-iKCs. Figure S7. Selection of BN-iKC colonies derived from BNoverexpressed UCs. Figure S8. Generation and long-term culture of BNiKCs derived from F-UCs in serum-free conditions. Figure S9. Differentiation potential of BN-FiKCs. Figure S10. RNA-sequencing analysis of BNiKCs. Figure S11. Reprogramming of fibroblasts into iKCs by using BN.

\section{Abbreviations}

iKC: induced keratinocyte like cell; B: BMI1; N: $\triangle N P 63 a ; K$ : KLF4; iPSC: induced pluripotent stem cell; EMT: Epithelial-mesenchymal transition; CFE: Colonyforming efficiency; HFSC: Hair follicle epithelial cell; KSFM: Keratinocyte serum free medium

\section{Acknowledgements}

Not applicable.

\section{Authors' contributions}

JZ, GS, IYK and SY conceived and designed this study; JZ, JP, PJK and GL performed the experiments; JZ, WY, IYK and SY analyzed and discussed the data; and JZ, IYK and SY wrote the manuscript; JZ, WY, IYK and SY revised the manuscript; All authors read and approved the manuscript.

\section{Funding}

This work (Grants No. C0421186) was supported by Business for Cooperative R\&D between Industry, Academy, and Research Institute funded Korea Small and Medium Business Administration in 20; This work was also supported by a Korea University Grant, School of Life Sciences and Biotechnology for BK21 PLUS, Korea University and STEMLAB, INC.

\section{Availability of data and materials}

All data generated in the current study are available from the corresponding author on reasonable request.
RNA-sequencing data has been submitted and deposited in Gene Expression Omnibus (GEO) under accession number GSE129316.

\section{Ethics approval and consent to participate}

Research procedure was approved by the Institutional Review Board of Korea University (No. 1040548-KU-IRB-17-31-A-2).

\section{Consent for publication}

Not applicable.

\section{Competing interests}

The authors declare that they have no conflict of interest.

\section{Author details}

${ }^{1}$ Laboratory of Cell Function Regulation, Department of Biotechnology, College of Life Sciences and Biotechnology, Korea University, Seoul 02841, Republic of Korea. ${ }^{2}$ Institute of Animal Molecular Biotechnology, College of Life Sciences and Biotechnology, Korea University, Seoul 02841, Republic of Korea. ${ }^{3}$ Department of Pathology, College of Medicine, Korea University Guro Hospital, Seoul 08308, Republic of Korea.

Received: 22 November 2019 Accepted: 26 March 2020

Published online: 20 April 2020

\section{References}

1. Van Loey NE, Van Son MJ. Psychopathology and psychological problems in patients with burn scars: epidemiology and management. Am J Clin Dermatol. 2003;4(4):245-72.

2. Leon-Villapalos J, Eldardiri M, Dziewulski P. The use of human deceased donor skin allograft in burn care. Cell Tissue Bank. 2010;11(1):99-104.

3. McCartan B, Dinh T. The use of split-thickness skin grafts on diabetic foot ulcerations: a literature review. Plast Surg Int. 2012;2012:715273.

4. Sun BK, Siprashvili Z, Khavari PA. Advances in skin grafting and treatment of cutaneous wounds. Science. 2014;346(6212):941-5.

5. Compton CC, et al. Skin regenerated from cultured epithelial autografts on full-thickness burn wounds from 6 days to 5 years after grafting. A light, electron microscopic and immunohistochemical study. Lab Investig. 1989; 60(5):600-12.

6. Wright KA, et al. Alternative delivery of keratinocytes using a polyurethane membrane and the implications for its use in the treatment of full-thickness burn injury. Burns. 1998;24(1):7-17.

7. Hata K. Current issues regarding skin substitutes using living cells as industrial materials. J Artif Organs. 2007;10(3):129-32.

8. Shakespeare PG. The role of skin substitutes in the treatment of burn injuries. Clin Dermatol. 2005;23(4):413-8.

9. Leventhal $\mathrm{A}$, et al. The benefits and risks of stem cell technology. Oral Dis. 2012;18(3):217-22.

10. Fong CY, Gauthaman K, Bongso A. Teratomas from pluripotent stem cells: a clinical hurdle. J Cell Biochem. 2010;111(4):769-81.

11. $\mathrm{Xu}$ J, Du $Y$, Deng $H$. Direct lineage reprogramming: strategies, mechanisms, and applications. Cell Stem Cell. 2015;16(2):119-34.

12. Chen Y, Mistry DS, Sen GL. Highly rapid and efficient conversion of human fibroblasts to keratinocyte-like cells. J Invest Dermatol. 2014;134(2):335-44.

13. Candi E, Schmidt R, Melino G. The cornified envelope: a model of cell death in the skin. Nat Rev Mol Cell Biol. 2005;6(4):328-40.

14. Potten CS, Booth C. Keratinocyte stem cells: a commentary. J Invest Dermatol. 2002;119(4):888-99.

15. Pincelli C, Marconi A. Keratinocyte stem cells: friends and foes. J Cell Physiol. 2010:225(2):310-5

16. Li A, et al. Extensive tissue-regenerative capacity of neonatal human keratinocyte stem cells and their progeny. J Clin Invest. 2004;113(3):390-400.

17. Terunuma A, et al. Efficient procurement of epithelial stem cells from human tissue specimens using a rho-associated protein kinase inhibitor $Y$ 27632. Tissue Eng Part A. 2010;16(4):1363-8.

18. Redvers RP, Li A, Kaur P. Side population in adult murine epidermis exhibits phenotypic and functional characteristics of keratinocyte stem cells. Proc Natl Acad Sci U S A. 2006;103(35):13168-73.

19. Blanpain C, et al. Self-renewal, multipotency, and the existence of two cell populations within an epithelial stem cell niche. Cell. 2004;118(5):635-48.

20. Ji X, et al. Urine-derived stem cells: the present and the future. Stem Cells Int. 2017;2017:4378947. 
21. Zhou T, et al. Generation of human induced pluripotent stem cells from urine samples. Nat Protoc. 2012;7(12):2080-9.

22. De Luca M, et al. Human epithelial cells induce human melanocyte growth in vitro but only skin keratinocytes regulate its proper differentiation in the absence of dermis. J Cell Biol. 1988;107(5):1919-26.

23. Roh C, et al. Multi-potentiality of a new immortalized epithelial stem cell line derived from human hair follicles. In Vitro Cell Dev Biol Anim. 2008; 44(7):236-44.

24. Trapnell C, Pachter L, Salzberg SL. TopHat: discovering splice junctions with RNA-Seq. Bioinformatics. 2009;25(9):1105-11.

25. Quinlan AR, Hall IM. BEDTools: a flexible suite of utilities for comparing genomic features. Bioinformatics. 2010;26(6):841-2.

26. Gentleman RC, et al. Bioconductor: open software development for computational biology and bioinformatics. Genome Biol. 2004;5(10):R80

27. Gangatirkar $P$, et al. Establishment of $3 D$ organotypic cultures using human neonatal epidermal cells. Nat Protoc. 2007;2(1):178-86.

28. Benny $P$, et al. Improving $2 \mathrm{D}$ and $3 \mathrm{D}$ skin in vitro models using macromolecular crowding. J Vis Exp. 2016;(114). https://doi.org/10.3791/ 53642.

29. Zhou T, et al. Generation of induced pluripotent stem cells from urine. J Am Soc Nephrol. 2011;22(7):1221-8.

30. Inoue $\mathrm{CN}$, et al. Reconstruction of tubular structures in three-dimensional collagen gel culture using proximal tubular epithelial cells voided in human urine. In Vitro Cell Dev Biol Anim. 2003;39(8-9):364-7.

31. Segre JA, Bauer C, Fuchs E. Klf4 is a transcription factor required for establishing the barrier function of the skin. Nat Genet. 1999;22(4):356-60.

32. Sen $G L$, et al. ZNF750 is a p63 target gene that induces KLF4 to drive terminal epidermal differentiation. Dev Cell. 2012;22(3):669-77.

33. Oh JE, et al. DeltaNp63alpha protein triggers epithelial-mesenchymal transition and confers stem cell properties in normal human keratinocytes. J Biol Chem. 2011;286(44):38757-67.

34. Molofsky AV, et al. Bmi-1 dependence distinguishes neural stem cell self-renewal from progenitor proliferation. Nature. 2003;425(6961):962-7.

35. Park IK, et al. Bmi-1 is required for maintenance of adult self-renewing haematopoietic stem cells. Nature. 2003;423(6937):302-5.

36. Lee $\mathrm{K}$, et al. Expression of Bmi-1 in epidermis enhances cell survival by altering cell cycle regulatory protein expression and inhibiting apoptosis. $J$ Invest Dermatol. 2008;128(1):9-17.

37. Reinisch CM, et al. Expression of BMl-1 in normal skin and inflammatory and neoplastic skin lesions. J Cutan Pathol. 2007;34(2):174-80.

38. Webb A, Li A, Kaur P. Location and phenotype of human adult keratinocyte stem cells of the skin. Differentiation. 2004;72(8):387-95.

39. Rheinwald JG, Green H. Serial cultivation of strains of human epidermal keratinocytes: the formation of keratinizing colonies from single cells. Cell. 1975;6(3):331-43.

40. International Stem Cell Initiative, C, et al. Comparison of defined culture systems for feeder cell free propagation of human embryonic stem cells. In Vitro Cell Dev Biol Anim. 2010;46(3-4):247-58.

41. Llames $\mathrm{S}$, et al. Feeder layer cell actions and applications. Tissue Eng Part B Rev. 2015;21(4):345-53.

42. Sciezynska A, et al. Isolation and culture of human primary keratinocytes - a methods review. Exp Dermatol. 2018;28(2):107-12.

43. De Corte $\mathrm{P}$, et al. Feeder layer- and animal product-free culture of neonatal foreskin keratinocytes: improved performance, usability, quality and safety. Cell Tissue Bank. 2012;13(1):175-89.

44. Boyce ST, Ham RG. Calcium-regulated differentiation of normal human epidermal keratinocytes in chemically defined clonal culture and serum-free serial culture. J Invest Dermatol. 1983;81(1 Suppl):33s-40s.

45. Usta SN, et al. Chemically defined serum-free and xeno-free media for multiple cell lineages. Ann Transl Med. 2014;2(10):97.

46. Bertolero F, et al. Effects of serum and serum-derived factors on growth and differentiation of mouse keratinocytes. In Vitro Cell Dev Biol. 1986;22(7):423-8.

47. Dlugosz AA, Yuspa SH. Coordinate changes in gene expression which mark the spinous to granular cell transition in epidermis are regulated by protein kinase C. J Cell Biol. 1993;120(1):217-25.

48. Vig K, et al. Advances in Skin Regeneration Using Tissue Engineering. Int J Mol Sci. 2017;18(4). https://doi.org/10.3390/ijms18040789.

49. Mathes $\mathrm{SH}$, Ruffner $\mathrm{H}$, Graf-Hausner $\mathrm{U}$. The use of skin models in drug development. Adv Drug Deliv Rev. 2014;69-70:81-102.
50. Graf T, Enver T. Forcing cells to change lineages. Nature. 2009;462(7273): 587-94.

51. Takahashi K, Yamanaka S. Induction of pluripotent stem cells from mouse embryonic and adult fibroblast cultures by defined factors. Cell. 2006;126(4): 663-76.

52. Takahashi $\mathrm{K}$, et al. Induction of pluripotent stem cells from adult human fibroblasts by defined factors. Cell. 2007;131(5):861-72.

53. Itoh $\mathrm{M}$, et al. Generation of keratinocytes from normal and recessive dystrophic epidermolysis bullosa-induced pluripotent stem cells. Proc Natl Acad Sci U S A. 2011;108(21):8797-802.

54. Yang $R$, et al. Generation of folliculogenic human epithelial stem cells from induced pluripotent stem cells. Nat Commun. 2014;5:3071.

55. Thier $M$, et al. Direct conversion of fibroblasts into stably expandable neural stem cells. Cell Stem Cell. 2012;10(4):473-9.

56. Bullock AJ, Higham MC, MacNeil S. Use of human fibroblasts in the development of a xenobiotic-free culture and delivery system for human keratinocytes. Tissue Eng. 2006;12(2):245-55.

57. Higham MC, et al. Development of a stable chemically defined surface for the culture of human keratinocytes under serum-free conditions for clinical use. Tissue Eng. 2003;9(5):919-30

58. Sun $T$, et al. Developments in xenobiotic-free culture of human keratinocytes for clinical use. Wound Repair Regen. 2004;12(6):626-34.

59. Cavazza A, Moiani A, Mavilio F. Mechanisms of retroviral integration and mutagenesis. Hum Gene Ther. 2013;24(2):119-31.

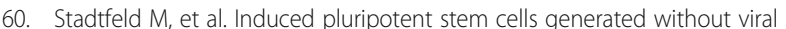
integration. Science. 2008;322(5903):945-9.

61. Fusaki $\mathrm{N}$, et al. Efficient induction of transgene-free human pluripotent stem cells using a vector based on Sendai virus, an RNA virus that does not integrate into the host genome. Proc Jpn Acad Ser B Phys Biol Sci. 2009; 85(8):348-62.

62. Lu J, et al. Generation of integration-free and region-specific neural progenitors from primate fibroblasts. Cell Rep. 2013;3(5):1580-91.

63. Loh $\mathrm{YH}$, et al. Excision of a viral reprogramming cassette by delivery of synthetic Cre mRNA. Curr Protoc Stem Cell Biol. 2012;Chapter 4:Unit4A 5.

64. Jia F, et al. A nonviral minicircle vector for deriving human iPS cells. Nat Methods. 2010;7(3):197-9.

65. Kaji K, et al. Virus-free induction of pluripotency and subsequent excision of reprogramming factors. Nature. 2009;458(7239):771-5.

66. Okita $\mathrm{K}$, et al. A more efficient method to generate integration-free human iPS cells. Nat Methods. 2011;8(5):409-12.

67. Wang $L$, et al. Generation of integration-free neural progenitor cells from cells in human urine. Nat Methods. 2013;10(1):84-9.

68. Warren $L$, et al. Highly efficient reprogramming to pluripotency and directed differentiation of human cells with synthetic modified mRNA. Cell Stem Cell. 2010;7(5):618-30.

69. Yoshioka $\mathrm{N}$, et al. Efficient generation of human iPSCs by a synthetic selfreplicative RNA. Cell Stem Cell. 2013;13(2):246-54.

70. Cheng $\mathrm{L}$, et al. Generation of neural progenitor cells by chemical cocktails and hypoxia. Cell Res. 2014;24(6):665-79.

71. Kang PJ, et al. Reprogramming of mouse somatic cells into pluripotent stem-like cells using a combination of small molecules. Biomaterials. 2014; 35(26):7336-45.

72. Zheng J, et al. A combination of small molecules directly reprograms mouse fibroblasts into neural stem cells. Biochem Biophys Res Commun. 2016;476(1):42-8.

73. Hou P, et al. Pluripotent stem cells induced from mouse somatic cells by small-molecule compounds. Science. 2013;341(6146):651-4.

74. Yang A, et al. p63 is essential for regenerative proliferation in limb, craniofacial and epithelial development. Nature. 1999;398(6729):714-8.

75. McDade SS, Patel D, McCance DJ. p63 maintains keratinocyte proliferative capacity through regulation of Skp2-p130 levels. J Cell Sci. 2011;124(Pt 10): 1635-43.

76. Antonini $\mathrm{D}$, et al. An autoregulatory loop directs the tissue-specific expression of p63 through a long-range evolutionarily conserved enhancer. Mol Cell Biol. 2006:26(8):3308-18.

77. Harmes DC, et al. Positive and negative regulation of deltaN-p63 promoter activity by p53 and deltaN-p63-alpha contributes to differential regulation of p53 target genes. Oncogene. 2003;22(48):7607-16.

78. Jaks $V_{\text {, et }}$ al. Lgr5 marks cycling, yet long-lived, hair follicle stem cells. Nat Genet. 2008;40(11):1291-9. 
79. Mardaryev AN, et al. Lhx2 differentially regulates Sox9, Tcf4 and Lgr5 in hair follicle stem cells to promote epidermal regeneration after injury. Development. 2011;138(22):4843-52.

80. Snippert $\mathrm{HJ}$, et al. Lgr6 marks stem cells in the hair follicle that generate all cell lineages of the skin. Science. 2010;327(5971):1385-9.

81. Vidal VP, et al. Sox9 is essential for outer root sheath differentiation and the formation of the hair stem cell compartment. Curr Biol. 2005;15(15):1340-51.

82. Nguyen $\mathrm{H}$, et al. Tcf3 and Tcf4 are essential for long-term homeostasis of skin epithelia. Nat Genet. 2009;41(10):1068-75.

83. Mistry DS, et al. SNAI2 controls the undifferentiated state of human epidermal progenitor cells. Stem Cells. 2014;32(12):3209-18

84. Bao X, et al. ACTL6a enforces the epidermal progenitor state by suppressing SWI/SNF-dependent induction of KLF4. Cell Stem Cell. 2013;12(2):193-203.

85. Sen GL, et al. DNMT1 maintains progenitor function in self-renewing somatic tissue. Nature. 2010:463(7280):563-7.

86. LeBoeuf $\mathrm{M}$, et al. Hdac1 and Hdac2 act redundantly to control p63 and p53 functions in epidermal progenitor cells. Dev Cell. 2010;19(6):807-18.

87. Ezhkova E, et al. Ezh2 orchestrates gene expression for the stepwise differentiation of tissue-specific stem cells. Cell. 2009;136(6):1122-35.

\section{Publisher's Note}

Springer Nature remains neutral with regard to jurisdictional claims in published maps and institutional affiliations.

Ready to submit your research? Choose BMC and benefit from:

- fast, convenient online submission

- thorough peer review by experienced researchers in your field

- rapid publication on acceptance

- support for research data, including large and complex data types

- gold Open Access which fosters wider collaboration and increased citations

- maximum visibility for your research: over $100 \mathrm{M}$ website views per year

At $\mathrm{BMC}$, research is always in progress.

Learn more biomedcentral.com/submissions 